\title{
Jay Hosler, An Evolutionary Novelty: Optical Allusions
}

\author{
Optical Allusions, by Jay Hosler. Columbus, OH: Active Synapse, 2008. \\ Pp 127. S/b \$20.00.
}

\author{
Todd H. Oakley
}

Published online: 16 October 2008

(C) Springer Science + Business Media, LLC 2008

The stereotypical scientist is focused: intensely focused. Imagine an aging white man with wild, graying hair and wide eyes behind thick, dark-rimmed glasses. He is so focused that nothing matters but science. A social life? Superfluous. Hobbies? Unnecessary. Fashion? "My neon pocket protector fits squarely in my lab coat." Stereotypes often have some basis in reality, but they over-simplify, ignoring the complexities of life. True, scientists are usually focused and driven. But they are also people, usually well-rounded, intelligent people. My scientist-colleagues are musicians, athletes, artists, and naturalists. They travel, play video games, and care for children. Yet (probably owing at least in part to my own unconscious predilection to stereotype), I am often surprised and awed when I find examples of scientists who excel in an arena decidedly different from scientific pursuits. Surprise and awe was exactly my reaction when Optical Allusions by Jay Hosler showed up in my mailbox, because the book displays not only Hosler's talent for teaching science but also for producing art.

My favorite thing about Optical Allusions is its originality. New things often come from the combination of established entities or traditions. Examples of this abound in the current issue of Evolution, Education and Outreach, as numerous articles describe how a major factor in the evolution of eyes is new combinations of existing biological components. Even inventors have fused existing things into something new, such as the lottery ticket-scratcher that is a combination of coin and key chain (Gregory 2008). The combination of comic book and educational scientific text,

\section{T. H. Oakley $(\bowtie)$}

Ecology Evolution and Marine Biology,

University of California-Santa Barbara,

Santa Barbara, CA 93106, USA

e-mail: oakley@lifesci.ucsb.edu which Hosler has also used in two previous books, is the fantastically novel idea explored in Optical Allusions to convey information about evolution, eyes, and vision in the context of a fun and creative comic story. Having a comic story that introduces science concepts is a great advantage for visual learners (like me). Hosler has used his comic illustrations to great effect, producing several highly memorable images that convey scientific concepts.

Combining comics and science is not the only original feature. The comic story itself is wildly inventive. The story follows the main character, Wrinkles the Wonder Brain, who is a brain without a person-no stranger than all the people walking around without a brain, as Wrinkles points out. Oh, and by the way, that is not his bottom. It is his cerebellum, thank you very much. In Chapter 1, Wrinkles quickly encounters trouble when he accidentally drops a magic eye into a vat of distilled human imagination. Armed with a bagful of newt eyes that allows him to go where and when he wants, Wrinkles plunges (ploops) into the vat to try to retrieve the lost magic eye. This is no easy task. Human imagination is vast, as Hosler demonstrates with this book.

In Chapter 2, Wrinkles meets Charles Darwin on an island, sitting behind a stand that Charles obviously acquired from Lucy van Pelt of Peanuts fame ("the doctor is IN"). Darwin teaches Wrinkles how to make an eye using evolution. This takes 364,000 years (but only one comic page), with Wrinkles and Charles acting as predators on little brains that gradually evolve complex eyes to help evade predation. Charles Darwin yelling "tuck in kid," before playing dominant predator on a gaggle of scurrying brains is one of the unforgettable images I mentioned (Fig. 1). This is all fine and good for Wrinkles, but after so many those millennia, he gets impatient. "When do the eyes become magical?" Wrinkles asks, anxious to find his lost 


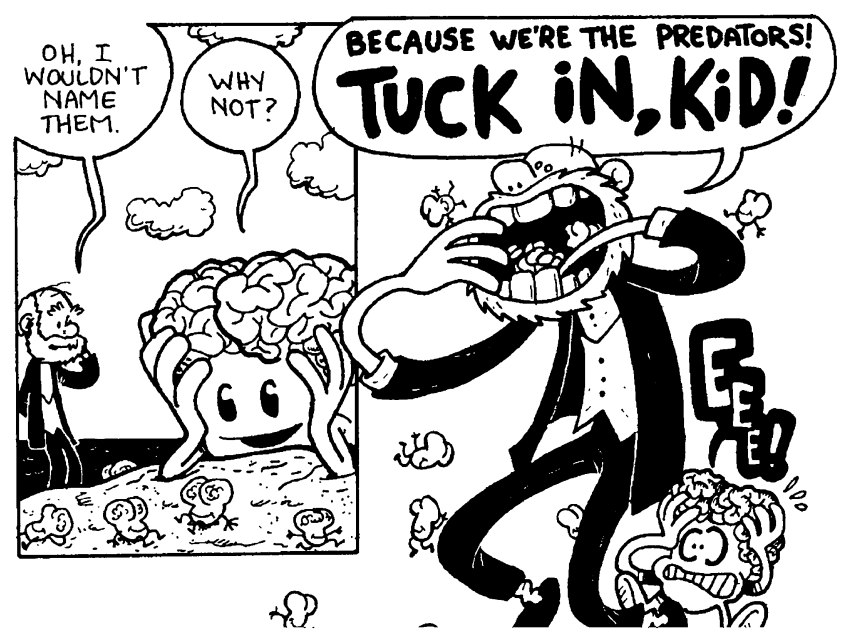

Fig. 1 Charles Darwin and Wrinkles the Wonderbrain play a friendly game of "Dominant Predator" to illustrate how natural selection can gradually produce something even as complex as an eye

magic eye. Darwin replies that magic only exists in books and suggests that Wrinkles find the mythical Cyclops of Homer's Odyssey. With a bite on one of the magic newt eyes, Wrinkles wishes to go to the Cyclops.

In Chapter 3, we discover that there is one problem with Wrinkles' wish: Cyclops is not only a mythical creature, but also a giant, killer eye-bot (spelled "C.Y.K.L.O.P.S.") built by an evil villain named "The Perfectionist" as an exact robotic replica of a human eye. The superhero Cow-boy recruits Wrinkles and together they seek to destroy the killer eye-bot who is wreaking havoc on the town of Pasteurville. The Perfectionist has created a perfect replica of a human eye that even includes perfectly replicated imperfections. This leads to one of my favorite images of the book. Wrinkles and Cow-boy make their way to the retina, and Cow-boy teaches Wrinkles about the eye-bot's perfectly copied blind spot. Cow-boy reaches down and yanks on a "cable" (a ganglion cell axon), uprooting a rod cell as if harvesting a carrot. "Why are rods buried beneath all those cables, shouldn't they face the light?" asks Wrinkles. Cow-boy shows Wrinkles the blind spot, where all axons are bundled together to make the optic nerve, which plunges down through the retina, leaving no place for any rods or cones in that place. These images provide an immediate understanding of why we have a blind spot (Fig. 2).

Another of these replicated imperfections of real human eyes becomes the eye-bot's Achilles heel. Cow-boy and Wrinkles find and block the Canal of Schlemm (which is labeled "Do Not Block"), producing a glaucoma that explodes the eye-bot. As Cow-boy hauls him away, The Perfectionist gets the last laugh by tricking Wrinkles into wishing he were tied up on a pirate ship. This wish comes true, and Wrinkles goes on to meet some pirates. But these are no ordinary pirates.

In Chapter 4, Wrinkles finds himself tied up on the deck of a pirate ship crewed by misfit stalk-eyed flies. After teaching the human captain and his wife that acquired traits (like lost limbs) are not passed to offspring, Wrinkles learns about the plight of the crew. Where they are from, there is strong discrimination - only the males with the longest eye stalks can mate. Long-stalked flies are better at fighting, and the females also prefer longer stalks, which might be an indicator of better genes. The flies' tale of heartache is a lesson for Wrinkles on sexual selection. But Wrinkles does not win any friends by bluntly distilling the flies' story as a description of "a bunch of wimpy, unattractive guys with bad genes." Those wimps also own a big cannon, which they use to shoot Wrinkles off the ship. A short time later, Wrinkles finds himself on another island.

This time, Wrinkles washes up on an island inhabited by Clio, the muse of history in Greek mythology. After another brief, but still striking visual, where Wrinkles demonstrates the function of his wrinkles by inflating, showing how they allow folding more brain into a small skull, Clio introduces Wrinkles to the Cyclops. This time, it is the Cyclops that Darwin suggested, Polyphemus. He goes by "Polly." Although Polly lost his eye in a battle with Odysseus, he has the support of a bunch of cave animals that lost their eyes naturally, over evolutionary time. Wrinkles meets a blind cave fish, and after donning a pair of X-ray specs, he learns how cavefish lens cells die during development. In other vertebrates, the lens signals to the optic cup, and without those signals, cavefish eyes do not develop
Fig. 2 Wrinkles the Wonderbrain ponders the imperfections of the human eye with super hero Cow-Boy

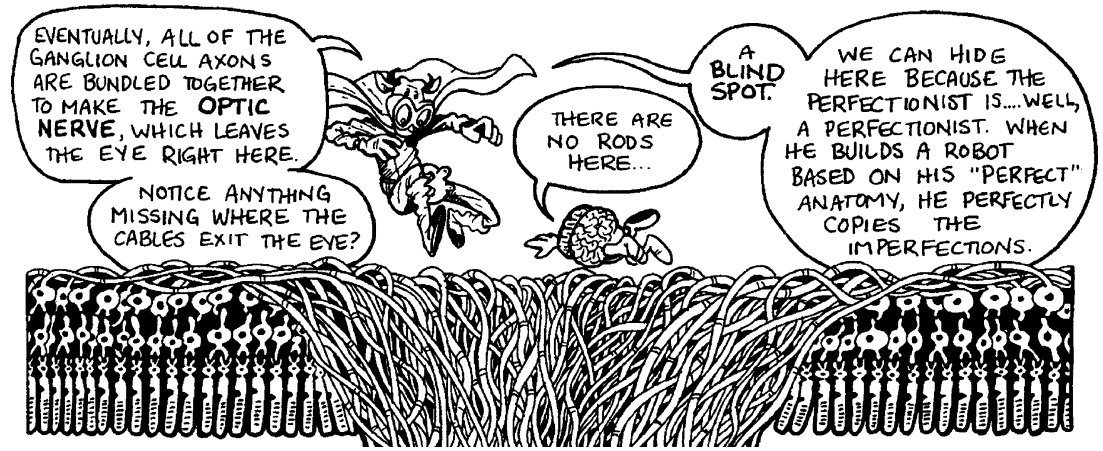


properly. Wrinkles learns that mutations that occurred during the evolution of cavefish favored more taste receptors at the expense of eyes, and this is probably the reason why cavefish lost their eyes during evolution. Clio asks Polly to take Wrinkles to the "cerebro-expand-omatic" (the library), so Wrinkles can devise a plan to find the lost magic eye. During his 5-year sabbatical, Wrinkles the brain creates a robotic body for himself. The mildly flirtatious Clio pinches Wrinkles' back side (the rear of his new robo-bod, not his cerebellum), revealing a fatal flaw: the butt-activated ejector seat. Wrinkles is abruptly sent into orbit.

In Chapter 6, Wrinkles meets the sun while in orbit. We learn about different kinds of radiation that the sun produces. Wrinkles apparently learned something on his 5 -year sabbatical in Clio's library because he eloquently explains how three different kinds of cone cells work together to produce color vision in humans. Wrinkles begins to feel the effects of the thin air at the edge of the atmosphere, so he bites another wish-granting newt eye, asking to be back down on Earth. When he lands, he finds that one of the Men In Black is convinced Wrinkles is an alien.

In Chapter 7, we learn that the man in black (Igor) actually works for Dr. Kleeshay, who plans to use a protein named Larry to take over the world. Larry is a selfdescribed "ginormous rhodopsin molecule engineered by Dr. Kleeshay." Some people call Larry the-here I can almost hear a dissonant organ chord to heighten the suspense, just before the squiggly text that reads- -Wereprotein." Larry, like any rhodopsin, can change shape.
Larry's shape changes when the retinal that is part of him is struck by light and changes itself. Next is another of my favorite sets of images, simple but effective. Hosler draws a pretty standard line representation of the chemical chromophore retinal, and Wrinkles shines a flashlight on it. In the next panel, the retinal straightens out, with motion lines and a sound effect, "ding." Later, when light shines on Larry (the rhodopsin were-protein), the retinal makes a "clink" sound, and Larry himself changes shape, howling at the moon (Fig. 3).

It turns out that Dr. Kleeshay is raising mutant zombie G-proteins, to be activated by Larry. Since a single opsin activates many G-proteins, which eventually lead to a photoreceptor sending a signal to the brain, Kleeshay plans to use Larry to turn millions into mindless zombie slaves. Luckily, Wrinkles knows that phosphates will quench rhodopsin signaling. Wrinkles adds phosphates to Larry, which happen to look like breasts in Hosler's drawings, leading Larry to change his name to Lariette. After saving Larry(ette), Wrinkles pops another newt eye and hastily wishes to be as far away from Dr. Kleeshay and Igor as possible.

In Chapter 8, Wrinkles finds himself frustrated and sitting beneath a large shady tree. Actually, he finds out that it is the tree, an idealized construct of the imagination, a Platonic type. The tree has been Yggdrasil, has dropped an apple on Newton, has eaten Charlie Brown's kites, and has shaded the Buddha. The tree is also phylogenetic trees, and it teaches Wrinkles how phylogenies are constructed, that there are no "lower animals" living today, only evolutionary survivors, and that lineages can converge separately on
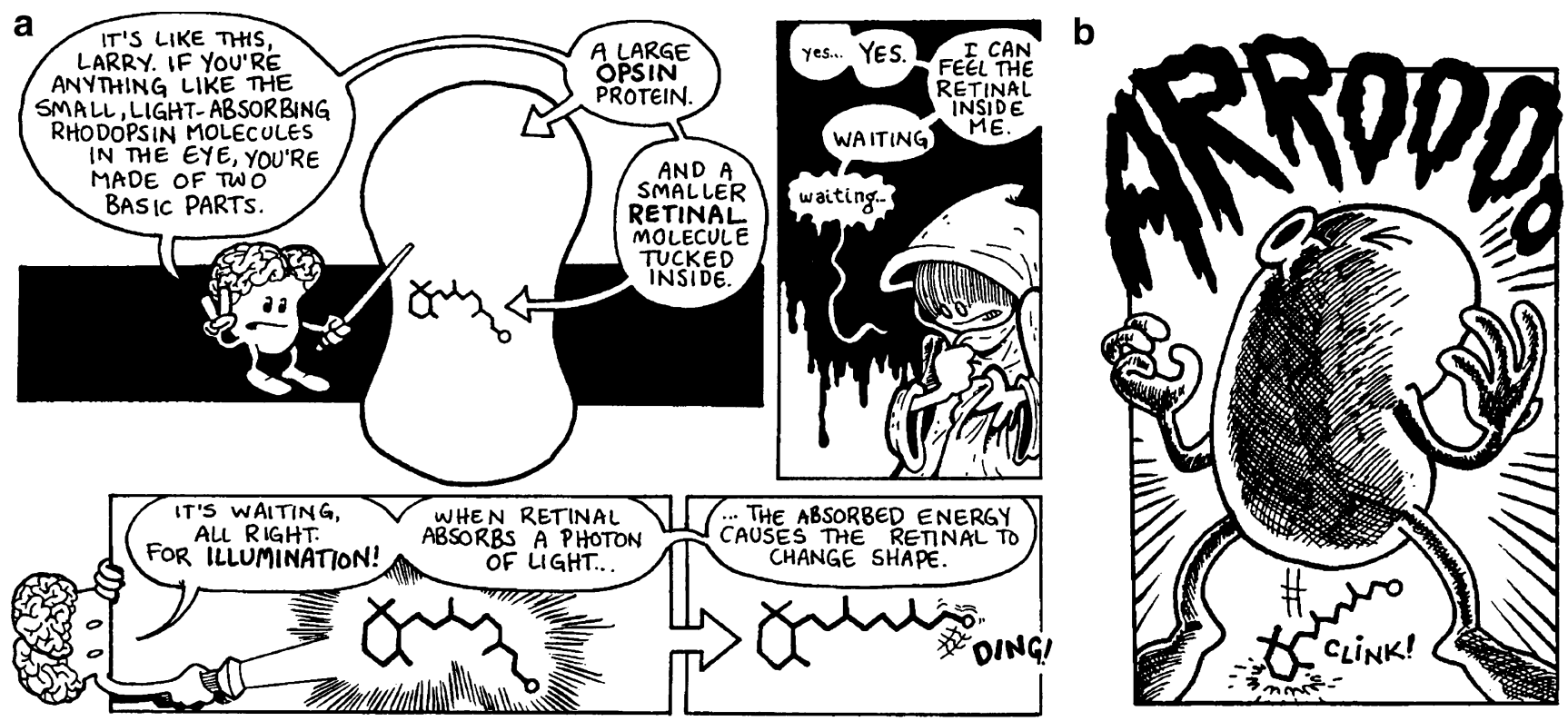

Fig. 3 a Larry the Were-protein is a giant rhodopsin molecule, complete with light reactive chemical, retinal. When light hits retinal, "ding," it changes shape. b Larry in his trans-state after being exposed to light. Dr. Kleeshay wants to exploit Larry’s Jeckyll and Hyde tendency to control the minds of millions 
similar forms during evolution. The tree also teaches Wrinkles that there is a unity to all life. For example, Pax-6 genes are involved in the development of most animal eyes studied so far. Wrinkles sees this similarity for himself when various animals spit out a ticker tape with their Pax-6 gene printed on it. All this information frustrates Wrinkles even more. He just wants to find the magic eye. But the tree inspires Wrinkles to simplify. Wrinkles has the wish-granting newt eyes, he just has to wish to go where the magic eye is. This works, but Wrinkles is alarmed to find out where the magic eye actually is. I would not reveal here the story of the last chapter, where Wrinkles finally finds the magic eye. I will only say that there is a (somewhat) happy ending. Wrinkles again encounters the flirtatious student of history from Chapter 5. She calls his "bottom" (cerebellum) adorable. Wrinkles is ecstatic, as anyone who is proud of their intelligence would be. After all, she likes Wrinkles for his brain.

The comic story is interleaved with text and figures describing in more detail the actual science behind Wrinkles' adventures. These cover a lot of scientific ground in a short time, using an unconventional, somewhat snarky and irreverent writing style, that I think many will find entertaining and informative.
I have essentially no criticisms of Optical Allusions. There were a few very minor errors of interpretation. For example, in cavefish, we do not know what is the precise mutation that causes a change in gene expression level, or if multiple mutations are involved. In addition, Pax is not "the gene" that coordinates all eye developmental genes. But these slight oversimplifications are inconsequential for the goals of this book. Optical Allusions seeks to present the wonders of science in a new way. Another minor criticism is that it is difficult to say who exactly the target audience is. But I expect any focused person, probably high schoolaged or older, with thick glasses, and a neon pocket protector in their lab coat, will have a great time reading Optical Allusions. Even though my own area of specialty is eye evolution, I learned some new things from this book. I was especially inspired with new teaching ideas using the comics. In the end, I very highly recommend this book for its entertainment and educational value.

\section{References}

Gregory TR. The evolution of complex organs. Evol Edu Outreach. 2008;1(4). doi:10.1007/s12052-008-0076-1. 